\title{
NGHIÊN CỨU ẢNH HƯởNG CỦA CÔNG TÁC KHAI THÁC CÁT, SỎI ĐẾN BIẾN ĐỘNG ĐƯỜNG BỜ SÔNG CHU (ĐOẠN CHẢY QUA HUYÊN THỌ XUÂN, TỈNH THANH HÓA) BẰNG DỮ LIỆU VIỄN THÁM
}

\author{
VƯONG TRỌNG KHA ${ }^{(1)}$, TRỊNH LÊ HÙNG(2), HOÀNG NGỌC HUY(3) \\ ${ }^{(1)}$ Truoòng Đại học Mỏ-Địa chất, ${ }^{(2)} H o c$ viện Kỹ thuật Quân sụ \\ ${ }^{(3)}$ Cục Đo đạc Bản đồ và Thông tin Địa lý Việt Nam
}

\section{Tóm tắt:}

Trong nhüng năm gần đây, tình trạng khai thác cát, sỏi tràn lan và thiếu quy hoạch dẫn đến sự sạt lở nghiêm trọng đường bò̀ các sông lớn ở Việt Nam. Bài báo này trình bày kết quả đánh giá biến động đường bờ sông Chu, đoạn chảy qua huyện Thọ Xuân (tỉnh Thanh Hóa) giai đoạn 2015 - 2020 tù̀ dũ liẹu viễn thám. 02 cảnh ảnh vệ tinh Sentinel-2A chup ngày 01/12/2015 và 09/03/2020 được sủ dụng đểxác định ranh giới nước - đất liền trên cơ sở chỉ số tự động tách nước AWEI, sau đó chồng xếp để phát hiện biến động đương bò̀ sông. Kết quả nhận được cho thấy, trong giai đoạn tù 2015 đến 2020, đường bò̀ sông Chu có sụ biến động rất phưc tạp, trong đó ghi nhận cả quá trình xói lở và bồi tụ. Tốc độ xói lở lớn nhất lên đến $37 \mathrm{~m} /$ năm ở trung tâm khu vục nghiên cưu, nơ tập trung các tàu hút cát, sỏi. Kết quả nhận được trong nghiên cứu có thể cung cấp thông tin giúp các nhà quản lý trong theo dõi, giám sát diễn biến sạt lở đường bờ sông Chu, làm cơ sở để đánh giá ảnh huởng của quá trình khai thác khoáng sản đến đường bò̀ sông.

\section{Mở đầu}

Những năm gần đây, quá trình đô thị hóa, xây dựng nông thôn mới...dẫn đến nhu cầu về vật liệu xây dựng rất lớn, khiến tình trạng khai thác cát, sỏi tại các sông lớn trên cả nước diễn ra hết sức phức tạp. Ở nhiều địa phương, việc khai thác cát, sỏi trái phép hoặc thiếu quy hoạch diễn ra trong thời gian dài, gây sạt lở bờ sông và ảnh hưởng nghiêm trọng đến đời sống cũng như hoạt động sản xuất của người dân. Việc theo dõi, giám sát sạt lở đường bờ sông do ảnh hưởng của khai thác cát, sỏi là một vấn đề có tính cấp thiết, cung cấp thông tin kịp thời giúp các nhà quản lý trong ứng phó với tình trạng trên.

Nhiều nghiên cứu trên thế giới đã sử dụng dữ liệu ảnh vệ tinh quang học như Landsat, Aster, Sentinel-2 trong xác định đường bờ sông, bờ biển, sau đó chồng xếp để tạo bản đồ biến động đường bờ (Huang et al., 2018) [5]. Ban đầu, phương pháp tổ hợp màu các kênh đỏ, cận hồng ngoại và hồng ngoại giữa được sử dụng nhằm tách ranh giới nước-đất liền thường do sự đơn giản trong xử lý. Mặc dù vậy, phương pháp này cũng có nhược điểm cơ bản khi không thể tự động tách được đối tượng nước, hơn nữa với những đối tượng nước có hình dạng phức tạp, việc số hóa từ ảnh tổ hợp màu gặp rất nhiều khó khăn (Feyisa et al., 2014). Alesheikh et al. (2007) [2] đã sử dụng các ảnh tỉ lệ từ các kênh xanh lục, đỏ, cận hồng ngoại ảnh vệ tinh Landsat trong đánh giá biến động đường bờ hồ Urmia (Azerbaijan) với độ chính xác đạt khoảng 1.3 pixel. Trên cơ sở phân tích đặc trưng phản xạ phổ của nước ở dải sóng nhìn thấy và hồng ngoại, nhiều nhà khoa học đã đề xuất các chỉ số nước như Normalized Difference Water Index (NDWI) (McFeeters, 1996 [6]; Gao, 1996 [4]), Modified Normalized Difference Water Index (MNDWI) $(\mathrm{Xu}, 2006)[10], .$. nhằm phân loại đối tượng nước mặt từ ảnh vệ tinh quang học. Mặc dù vậy, việc lựa chọn giá trị ngưỡng để phân biệt giữa nước và đất liền trên các chỉ số nước này là một vấn đề khó khăn do giá trị 
ngưỡng thay đổi theo thời gian và không gian (Feyisa et al., 2004).

Từ phân tích những hạn chế của các chỉ số nước như NDWI, MNDWI, Feyisa et al. (2014) [3] đã đề xuất sử dụng chỉ số tách nước tự động (AWEI - Automated Water Extraction Index) nhằm cung cấp giá trị ngưỡng ổn định, từ đó cải thiện độ chính xác khi tách nước - đất liền. Chỉ số AWEI cũng được sử dụng trong một số nghiên cứu (Acharya et al., 2018 [1]; Mustafa et al. 2017 [7]; Nguyen et al., 2019 [8]; Trinh et al., 2020 [9]) và chứng minh tính hiệu quả khi so sánh với các chỉ số nước khác.

Bài báo này trình bày kết quả đánh giá biến động đường bờ sông Chu, đoạn chảy qua huyện Thọ Xuân, tỉnh Thanh Hóa từ dữ liệu ảnh vệ tinh Sentinel-2A giai đoạn 2015 - 2020. Chỉ số nước AWEInsh xác định từ 02 cảnh ảnh Sentinel-2A ngày $01 / 12 / 2015$ và $09 / 03 / 2020$ được sử dụng để tách ranh giới nước - đất liền, sau đó chồng xếp để xây dựng bản đồ biến động đường bờ sông Chu khu vực nghiên cứu giai đoạn 2015 - 2020.

\section{Phương pháp nghiên cứu}

Đặc trưng phản xạ phổ của nước có sự khác biệt rất lớn so với các đối tượng lớp phủ bề mặt khác (đất, thực vật), trong đó nước hấp thụ phần lớn năng lượng bức xạ điện từ chiếu tới ở bước sóng cận hồng ngoại và hồng ngoại sóng ngắn (Hình 1).

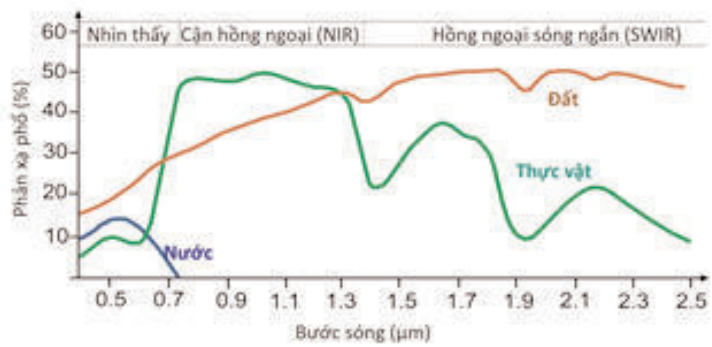

Hình 1: Đặc trung phản xạ phổ của nước và các đối tượng mặt đất

Các thực thể nước bề mặt cũng rất đa dạng, được bao quanh bởi thực phủ khác nhau và có đặc trưng phản xạ phổ khác nhau. Dựa vào ý tưởng này, cùng với các khảo sát chi tiết, Feyisa et al. (2014) [3] đã sử dụng năm kênh ảnh Landsat TM để xây dựng chỉ số tách nước tự động AWEI, bao gồm các kênh xanh lam (kênh 1), xanh lục (kênh 2), cận hồng ngoại (kênh 4) và 2 kênh hồng ngoại sóng ngắn (kênh 5 và kênh 7). Chỉ số này bao gồm hai chỉ số là $\mathrm{AWEI}_{\mathrm{sh}}$ (sử dụng cho đối tượng nước bị ảnh hưởng của bóng do thực phủ gây nên) và $\mathrm{AWEI}_{\text {nsh }}$ (sử dụng cho đối tượng nước không bị ảnh hưởng bởi bóng của thực phủ) (Acharya et al., 2018) [1]. Với đường bờ sông ít bị ảnh hưởng của thực vật, trong nghiên cứu này lựa chọn sử dụng chỉ số $\mathrm{AWEI}_{\mathrm{nsh}}$ để xác định ranh giới nước - đất liền và đánh giá biến động đường bờ.

Chỉ số $\mathrm{AWEI}_{\mathrm{nsh}}$ được xác định như sau:

$$
A W E I_{1 z h}=4\left(\rho_{B 2}-\rho_{B 11}\right)-0.25 \rho_{B 8}+2.75 \rho_{B 12}
$$

Trong đó, $\rho$ là giá trị phản xạ phổ của các kênh xanh lục (B2), cận hồng ngoại (B8), hồng ngoại sóng ngắn $(\mathrm{B} 11, \mathrm{~B} 12)$ ảnh vệ tinh Sentinel-2A. Như vậy, để tính chỉ số $\mathrm{AWEI}_{n \text { sh }}$, giá trị số nguyên của ảnh vệ tinh Sentinel-2A cần được chuyển đổi về giá trị phản xạ phổ. Do ảnh Sentinel-2A được cung cấp ở mức độ xử lý L2A (đã chuyển từ giá trị số nguyên sang phản xạ đỉnh khí quyển), trong nghiên cứu chỉ tiến hành hiệu chính khí quyển để xác định giá trị phản xạ bề mặt nước bằng phần mềm SNAP. Quá trình tính toán chỉ số $\mathrm{AWEI}_{\mathrm{nsh}}$ được tiến hành trên phần mềm ERDAS Imagine 2014. Giá trị ngưỡng nhằm phân biệt ranh giới nước - đất liền được lấy trên cơ sở phân tích histogram các ảnh chỉ số $\mathrm{AWEI}_{n \text { sh }}$ trên phần mềm ENVI 5.2.

Sau khi xác định chỉ số nước $\mathrm{AWEI}_{\mathrm{nsh}}$, giá trị ngưỡng sẽ được lựa chọn để tách ranh giới nước - đất liền. Kết quả nhận được là một ảnh ở dạng nhị phân, trong đó nước có giá trị là 1 , đất liền có giá trị là 0 . Các ảnh tiếp tục được vector hóa và chồng xếp để nhận được kết quả xác định biến động đường bờ. Bản đồ biến động đường bờ sông Chu giai đoạn 2015 - 2020 được xây dựng trên phần mềm ArcGIS 10.

\section{Kết quả và thảo luận}


Khu vực nghiên cứu được lựa chọn là sông Chu đoạn chảy qua huyện Thọ Xuân (tỉnh Thanh Hóa). Đây là địa bàn đang diễn ra tình trạng khai thác cát, sỏi rầm rộ và phức tạp trong thời gian qua, ảnh hưởng lớn đến môi trường sống và hoạt động sản xuất của người dân địa phương.

Dữ liệu viễn thám sử dụng trong nghiên cứu bao gồm 02 cảnh ảnh vệ tinh Sentinel-2A ở mức xử lý L2A, chụp ngày $01 / 12 / 2015$ (hình 2) và 09/03/2020 (Hình 3). Ảnh được chụp vào mùa khô, không bị ảnh hưởng bởi mây và sương mù. Sau khi thu thập và tiền xử lý nhằm xác định giá trị phản xạ phổ bề mặt, ảnh được cắt theo khu vực nghiên cứu và tính toán chỉ số $\mathrm{AWEI}_{\mathrm{nsh}}$ theo công thức (1).

Kết quả xác định chỉ số $\mathrm{AWEI}_{n \text { sh }}$ khu vực nghiên cứu từ ảnh vệ tinh Sentinel-2A ngày $01 / 12 / 2015$ và $09 / 03 / 2020$ được trình bày trên các hình 4 và 5 . Trên ảnh chỉ số $\mathrm{AWEI}_{\mathrm{nsh}}$, nước được thể hiện bởi màu trắng sáng, trong khi thực vật và đất được thể hiện bởi các pixel màu tối.



Hình 2: Anh Sentinel-2A ngày 01/12/2015 khu vục nghiên cúu

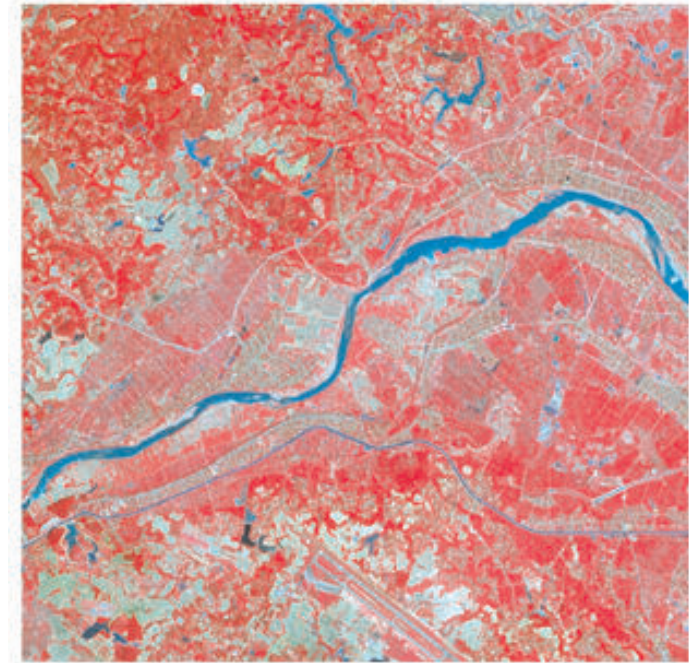

Hình 3: Anh Sentinel-2A ngày 09/03/2020 khu vục nghiên cúu

Căn cứ vào biểu đồ histogram của ảnh chỉ số nước $\mathrm{AWEI}_{\mathrm{nsh}}$, trong nghiên cứu tiến hành lựa chọn ngưỡng để phân loại lớp nước và lớp không phải nước. Giá trị ngưỡng này được đưa vào để phân loại, trong các điểm ảnh có giá trị nhỏ hơn ngưỡng khảo sát được đưa về lớp không phải nước, ngược lại nếu lớn hơn ngưỡng khảo sát thì sẽ thuộc về lớp nước. Các sai số lấy thừa và bỏ sót được tính nhằm tìm ra ngưỡng tối ưu. Việc quyết định ngưỡng nào là tối ưu sẽ căn cứ vào sai số lấy thừa và sai số bỏ sót. Thông thường khi sai số lấy thừa lớn thì sai số bỏ sót sẽ nhỏ và ngược lại. Do đó, ngưỡng tối ưu sẽ là ngưỡng mà cho kết quả phân loại có sai số lấy thừa bằng sai số bỏ sót.

Phân tích các ảnh chỉ số $\mathrm{AWEI}_{n \text { sh }}$ khu vực thử nghiệm cho thấy, ngưỡng tối ưu để tách lớp nước và đất liền là 0,1108 . Ảnh nhị phân thể hiện kết quả phân ngưỡng nước - đất liền từ chỉ số AWEInsh năm 2015 và 2020 được trình bày trên hình 6 , trong đó nước có màu trắng (giá trị 1 ) và đất liền có màu đen (giá trị 0 ). Quá trình thử nghiệm với các giá trị ngưỡng khác nhau nhằm lựa chọn ngưỡng tối ưu được thực hiện trên phần mềm xử lý ảnh ENVI 5.2. 


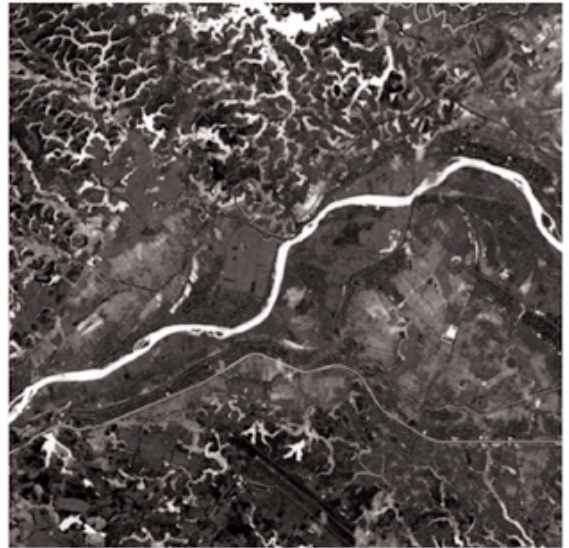

Hình 4: Chỉ số nước AWEI ${ }_{n s h}$ xác định tù̀ ảnh Sentinel-2A ngày 01/12/2015

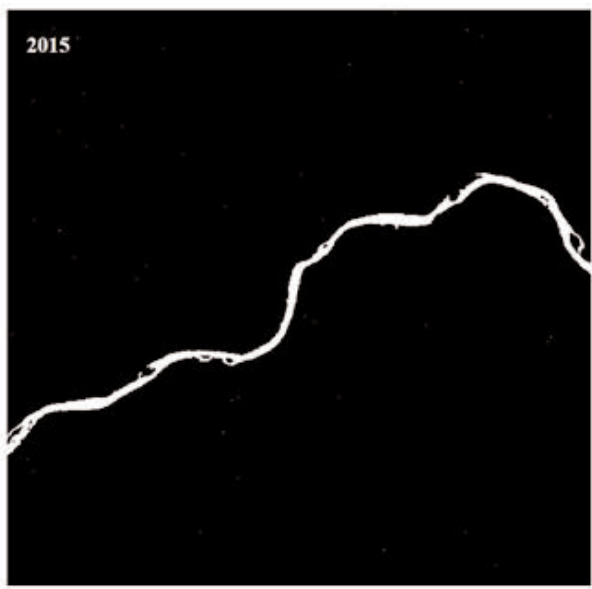

Hình 6: Kết quả phân ngữ̛ng nước-đất liền tì ảnh chỉ số AWEI ${ }_{n s h}$
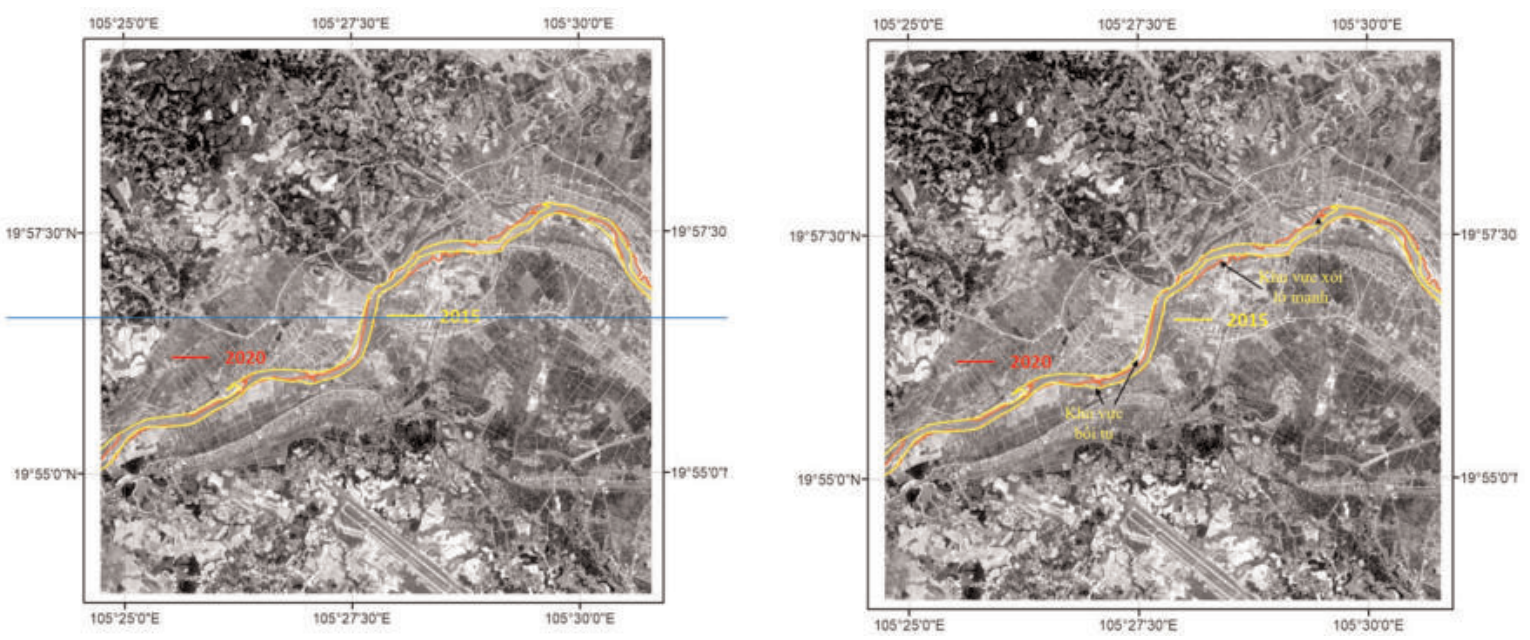

Hình 7: Kết quả đánh giá biến động đương bờ sông Chu đoạn chảy qua huyện Thọ Xuân, tỉnh Thanh Hóa tù ảnh vệ tinh Sentinel-2A giai đoạn 2015 - 2020 
Kết quả đánh giá biến động đường bờ sông Chu đoạn chảy qua huyện Thọ Xuân, tỉnh Thanh Hóa giai đoạn 2015 - 2020 từ dữ liệu ảnh vệ tinh Sentinel-2A được trình bày trên hình 7 . Phân tích kết quả nhận được cho thấy, chỉ trong một khoảng thời gian ngắn (5 năm), đường bờ sông Chu có sự thay đổi rất lớn, trong đó ghi nhận cả quá trình sạt lở và bồi tụ. Đoạn phía tây khu vực nghiên cứu, đường bờ sông tương đối ổn định trong giai đoạn 2015-2020, trong đó một số khu vực diễn ra quá trình bồi tụ với tốc độ khoảng 20 m/năm. Tốc độ xói lở đường bờ sông ở đoạn phía tây khu vực nghiên cứu nhìn chung không đáng kể, dưới 5 m/năm.

Ngược lại, đường bờ sông ở trung tâm khu vực nghiên cứu có sự biến động khá lớn với xu hướng chung là sạt lở. Trong giai đoạn 2015 2020, chiều dài đoạn sạt lở lớn nhất đạt gần 1000 $\mathrm{m}$, chiều sâu rộng chỗ lớn nhất đạt khoảng 175 $\mathrm{m}$, tốc độ sạt lở trung bình là $37 \mathrm{~m} / \mathrm{năm}$. Nhiều đoạn sông ở trung tâm khu vực nghiên cứu cũng ghi nhận tốc độ sạt lở trên 20 m/năm. Đoạn phía tây khu vực nghiên cứu, tốc độ sạt lở đường bờ sông có giảm xuống mặc dù vẫn cao, một số chỗ cũng ghi nhận cả hiện tượng bồi tụ với tốc độ khá nhanh. Kết quả này cũng phù hợp với diễn biến khai thác cát, sỏi ở sông Chu thời gian qua, khi các máy hút cát, sỏi tập trung phần lớn ở đoạn trung tâm khu vực nghiên cứu, thuộc địa bàn các xã Phú Xuân, Xuân Lai và Hạnh Phúc. Như vậy, có thể nhận thấy, việc khai thác cát, sỏi ở sông Chu đã có những ảnh hưởng đáng kể đến dòng chảy và lòng sông, dẫn đến những diễn biến rất phức tạp của đường bờ sông Chu trong một giai đoạn ngắn, từ năm 2015 đến năm 2020 .

Kết quả nhận được trong nghiên cứu cũng cho thấy tính hiệu quả của việc sử dụng dự liệu ảnh viễn thám độ phân giải cao Sentinel-2 MSI trong nghiên cứu, đánh giá biến động đường bờ. Do được cung cấp hoàn toàn miễn phí, chu kỳ cập nhật ngắn (5 ngày), độ phân giải không gian cao (lên đến $10 \mathrm{~m}$ ) và số lượng kênh phổ lớn (13 kênh), ảnh Sentinel-2 MSI đang dần trở thành nguồn dữ liệu quan trọng trong nghiên cứu, giám sát tài nguyên và môi trường. Với những nghiên cứu ở những khu vực có diện tích không lớn, việc sử dụng ảnh vệ tinh Sentinel-2 MSI cũng phù hợp và hiệu quả hơn so với sử dụng dữ liệu ảnh vệ tinh Landsat - nguồn dữ liệu chủ đạo trong các nghiên cứu về biến động đường bờ sông, bờ biển trước đây.

\section{Kết luận}

Trong nghiên cứu này, 02 cảnh ảnh vệ tinh Sentinel-2A giai đoạn 2015 - 2020 khu vực sông Chu đoạn chảy qua huyện Thọ Xuân (tỉnh Thanh Hóa) được sử dụng để chiết tách đường bờ trên cơ sở chỉ số tách nước tự động $\mathrm{AWEI}_{\mathrm{nsh}}$. Các đường bờ được chồng xếp và phân tích nhằm đánh giá biến động trong 5 năm, từ năm 2015 đến 2020. Kết quả nhận được cho thấy, đường bờ sông Chu khu vực nghiên cứu có những diễn biến rất phức tạp trong một khoảng thời gian ngắn, trong đó ghi nhận cả hiện tượng sạt lở và bồi tụ. Đoạn sông trung tâm khu vực nghiên cứu, nơi tập trung các máy, tàu khai thác cát, sỏi trong thời gian qua, xu hướng biến động đường bờ sông chủ đạo là sạt lở, với những khu vực có tốc độ sạt lở lên đến gần $40 \mathrm{~m} / \mathrm{năm}$, chiều dài sạt lở lên đến gần 1000 m. Với những khu vực còn lại, tốc độ sạt lở có thấp hơn nhưng vẫn còn cao. Trong khi đó, quá trình bồi tụ diễn ra chủ yếu ở đoạn phía tây khu vực nghiên cứu.

Kết quả nhận được trong nghiên cứu là nguồn thông tin quan trọng giúp các nhà quản lý trong phát hiện, giám sát hiện tượng sạt lở đường bờ sông Chu, từ đó đưa ra các biện pháp kịp thời trong giảm thiểu ảnh hưởng do khai thác cát, sỏi đến biến động đường bờ sông. $\mathrm{O}$

\section{Tài liệu tham khảo}

[1]. Acharya T., Subedi A., Lee D. (2018). Evaluation of water indices for surface water extraction in a Landsat 8 scence of Nepan, Sensors, 18(8):2580.

[2]. Alesheikh A., Ghorbanali A., Nouri A. (2007). Coastline change detection using remote sensing, International Journal of Environmental Science and Technology, 4(1), $61-66$.

[3]. Feyisa G., Meiby H., Fensholt R., Proud 
S. (2014). Automated water extraction index: A new technique for surface water mapping using Landsat imagery, Remote Sensing of Environment, Vol. 140, 23 - 35

[4]. Gao B.C. (1996). NDWI - A normalized difference water index for remote sensing of vegetation liquid water from space, Remote Sensing of Environment 58, 257 - 266.

[5]. Huang C., Chen Y., Zhang S., Wu J. (2018). Detecting, Extracting, and Monitoring Surface Water From Space Using Optical Sensors: A Review, Reviews of Geophysics, Vol. 56(2), $333-360$.

[6]. McFeeters, S. K. (1996). The use of the Normalized Difference Water Index (NDWI) in the delineation of open water features, International Journal of Remote Sensing, 17(7), 1425-1432.

[7]. Mustafa M., Hassoon K., Hussain H., Modher H. Abd (2017). Using water indices (NDWI, MNDWI, WRI and AWEI) to detect physical and chemical parameters by apply remote sensing and GIS techniques, International Journal of Research Granthalayah, Vol. 5(10), 117 - 128.

[8]. Nguyen U.N.T., Pham L.T.H., Dang T.D. (2019). An automatic water detection approach using Landsat 8 OLI and Google Earth Engine cloud computing to map lakes and reservoirs in New Zealand, Environmental Monitoring and Assessment, Vol. 191(4):235.

[9]. Trinh Le Hung, Le T.G., Kieu V.H., Tran T.M.L., Nguyen T.T.N. (2020). Application of remote sensing technique for shoreline change detection in Ninh Binh and Nam Dinh provinces (Vietnam) during the period 1988 to 2018 based on water indices, Russian Journal of Earth Sciences, Vol. 20(2), 1-15.

[10]. Xu H. (2006). Modification of normalised difference water index (NDWI) to enhance open water features in remotely sensed imagery, International Journal of Remote Sensing, 27(14), 3025-3033. 0

\section{Summary}

Research for the impact of sand and gravel mining on Chu river bank change (in the intersection at Tho Xuan district, Thanh Hoa province) using remote sensing data

Vuong Trong Kha, Hanoi University of Mining and Geology

Trinh Le Hung, Military Technical Academy

Hoang Ngoc Huy, Department of Survey, Mapping and Geographic information Vietnam

In recent years, the widespread mining of sand and gravel have led to serious erosion of the banks of major rivers in Vietnam. This paper presents the results of shoreline changes in the section of Chu river, which running through Tho Xuan district (Thanh Hoa province) in period 2015 - 2020 from remote sensing data. 02 Sentinel-2A satellite images taken on 01/12/2015 and 09/03/2020 were used to extract the water/land boundary based on the Automated Water Extraction Index (AWEI), then overlay to detect change in riverbank condition. The results show that, the Chu river bank has complicated change in period 2015 - 2020, including erosion and accretion processes. The maximum erosion rate is up to $37 \mathrm{~m} /$ year in the center of the study area, where sand and gravel ships are concentrated. The results obtained in the study can provide information to help managers in monitoring the riverbank change of Chu river, as a basis for assessing the impact of mining process on riverbank. $\bigcirc$ 